\title{
INHIBITION OF SYMPATHETIC PREGANGLIONIC NEURONS BY CATECHOLAMINES AND CLONIDINE: MEDIATION BY AN $\alpha$-ADRENERGIC RECEPTOR ${ }^{1}$
}

\author{
PATRICE G. GUYENET*, ${ }^{*}$ AND JOHN B. CABOT $\ddagger$ \\ *Department of Pharmacology, University of Virginia School of Medicine, Charlottesville, Virginia 22908 and $\ddagger$ Departmenl of Neurobiology \\ and Behavior, State University of New York at Stony Brook, Stony Brook, New York 11794
}

\begin{abstract}
The neuropil surrounding sympathetic preganglionic neurons (SPNs) receives an abundant catecholaminergic innervation originating from the brain stem. The effect of catecholamines (CA) released at this spinal level on the activity of SPNs is still controversial as is the extent to which this particular CA transmission is affected by central antihypertensive drugs, such as clonidine and $\alpha$ methyldopa. The present study was initiated, therefore, to determine the effects of iontophoretic applications of CAs and clonidine on the discharges of identified SPNs and to determine the type of receptor mediating the action of these compounds.

Extracellular recordings were made with five- or six-barrel electrodes in 20 pigeons anesthetized with urethane, artificially ventilated, and immobilized. Data were obtained on 83 SPNs localized in the three first thoracic segments and identified on the basis of constancy of antidromic activation latency and collision.

All of the cells sampled were inhibited by the application of low iontophoretic currents of clonidine and by a series of CAs, including $\alpha$-methylnorepinephrine, epinephrine, norepinephrine, and phenylephrine.

For each compound, the amount of charge necessary to decrease the level of cell firing to $50 \%$ of control was calculated. Using this value as an index of drug potency, the following rank order could be determined: clonidine $>\alpha$-methylnorepinephrine $>$ epinephrine $>$ norepinephrine $>$ phenylephrine.

The inhibitory effects of both clonidine and norepinephrine were antagonized by iontophoretic applications of the $\alpha$ antagonists, yohimbine, piperoxan, and phentolamine. In contrast, the $\beta$ antagonist, sotalol, and the $\alpha_{1}$ antagonist, prazosin, were found ineffective when similarly applied.

It is concluded that CAs and clonidine are inhibitory to the maintained activity of SPNs and that an $\alpha_{2}$-adrenergic receptor may be involved in the action of these compounds.
\end{abstract}

Central nervous system (CNS) catecholamine pathways participate in the tonic and phasic modulation of cardiovascular function (Chalmers, 1975; Hauesler, 1977; Loewy and McKellar, 1980; Reis et al., 1977). However, the exact role of the individual pathways and their mechanism(s) of action are not well defined. This problem is exemplified by the conflicting data surrounding the physiological role of the dense bulbospinal noradrenergic (NE) and adrenergic (E) projections to the sympathetic preganglionic cell column in mammalian as well as avian

\footnotetext{
${ }^{1}$ This research was supported in part by National Institute of Drug Abuse Grant DA02310-02 (to P. G. G.) and National Institutes of Health Grant HL 241.03 (to J. B. C.). We thank Noah Bogan for his aid with the illustrations.

${ }^{2}$ To whom correspondence should be addressed at Department of Pharmacology, University of Virginia School of Medicine, 1300 Jefferson Park Avenue, Charlottesville, VA 22908.
}

species (Dahlstrom and Fuxe, 1965; Hökfelt et al., 1974; Zivin et al., 1975; Caserta and Ross, 1978). Some reports suggest that the NE input to the preganglionic neuropil is excitatory (Neumayr et al., 1974; Taylor and Brody, 1976; Loewy et al., 1979), while other evidence implies that NE is inhibitory (Coote and MacLeod, 1974, 1977). Still another hypothesis has been forwarded in which NE and $\mathrm{E}$ would have opposite effects, with $\mathrm{E}$ being inhibitory and NE being excitatory (Fuxe et al., 1975). In addition, a limited amount of iontophoretic data is available and indicates that some preganglionic neurons are inhibited by NE but that the majority appear to be unaffected (Hongo and Ryall, 1966; DeGroat and Ryall, 1967).

Of some immediate interest is the extent to which these bulbospinal catecholaminergic pathways are affected by centrally acting antihypertensive drugs. One such commonly used agent is clonidine, 2-[(2,6-dichloro- 
phenyl)amino]-2-imidazoline (Schmitt, 1977). Its hypotensive effects are due primarily to a reduction in sympathetic tone, resulting in decreased peripheral resistance. The exact site(s) of the sympathoinhibitory action of clonidine is poorly understood, though the drug is generally believed to act principally within the medulla (Schmitt, 1977; Kobinger, 1978). However, there is good evidence for a direct action at the level of the spinal cord as well (Hauesler, 1974; Franz et al., 1978). Most peripheral and CNS actions of clonidine appear to be due to its interaction with $\alpha$-adrenergic receptors (Langer et al., 1980), and indeed, the drug is a partial agonist at $\alpha_{1}$ adrenergic peripheral (Ruffolo et al., 1979) and central (Rogawski and Aghajanian, 1980) receptors and a very potent agonist at $\alpha_{2}$ peripheral presynaptic receptors (Starke, 1977). The remarkable sympathoinhibitory potency of clonidine and the fact that its effect can be fully reversed by yohimbine, an $\alpha$ antagonist with a relative specificity for $\alpha_{2}$ receptors at the periphery, suggest the yet undemonstrated possibility that its hypotensive actions could result from an interaction with $\mathrm{CNS} \alpha_{2}$-like receptors (Schmitt, 1977; Langer et al., 1980). 'The presence within the CNS of receptors with properties similar to the $\alpha_{2}$ peripheral presynaptic receptors has been demonstrated recently in the rat locus coeruleus (Cedarbaum and Aghajanian, 1977) and is supported by radioligand binding studies (Miach et al., 1978; Young and Kuhar, 1980).

The following experiments were initiated to study the effect of clonidine, NE, and other catecholamines on the discharge of sympathetic preganglionic neurons and to determine the nature of the receptors involved in their action at this level.

\section{Materials and Methods}

Experimental animals. Experiments involved 20 white Carneaux pigeons (Columba livia) ranging in age from 2 to 6 months and weighing 400 to 700 gin. The birds were obtained from the Palmetto Pigeon Plant, Sumter, SC and were treated with antibiotics for 30 days prior to experimentation.

General procedures. Anesthesia was induced with $15 \%$ urethane $(1.5 \mathrm{gm} / \mathrm{kg}$, i.p.), after which, the trachea was intubated and positive pressure ventilation was applied at a ratio of 25 to $30 / \mathrm{min}$ with a constant tidal volume of $10 \mathrm{ml}$. The right or left brachial vein was cannulated and birds were immobilized by the intravenous administration of either a single dose of an avian saline solution of $\alpha$-bungarotoxin $(0.2$ to $0.5 \mathrm{mg} / \mathrm{kg})$ or pancuronium bromide $(1 \mathrm{mg} / \mathrm{kg}$ initially with supplemental doses of 0.3 $\mathrm{mg} / \mathrm{kg}$ as needed). Immobilization drugs were administered over a 20 - to $40-\mathrm{min}$ period at a rate of $2.4 \mathrm{ml} / \mathrm{hr}$. For the remainder of the experiment, a $6 \%$ dextrose solution was infused continuously ( 1 to $2 \mathrm{ml} / \mathrm{hr}$ ). Body temperature was maintained between 37 and $41^{\circ} \mathrm{C}$ with a thermostatically controlled heating pad and the EKG (Lead II) was monitored.

Single unit recordings and iontophoresis. The techniques involved have been described before (Guyenet and Aghajanian, 1978; Guyenet, 1980); therefore, only a few details of procedure will be presented. Five-barrel (tip size $\simeq 2 \mu \mathrm{m}$ ) or six-barrel glass pipettes were used for extracellular recording and iontophoresis. Six-barrel electrodes consisted of a five-barrel pipette (tip size $\simeq 10$ to $20 \mu \mathrm{m}$ ) glued alongside of a single barrel pipette (tip size $\simeq 1 \mu \mathrm{m}$ ), with the latter protruding 25 to $40 \mu \mathrm{m}$ from the first and used for recording. Six-barrel electrodes were found to provide superior isolation of preganglionic spikes (signal/noise ratio of up to $40 / 1$ ) and the larger size of the iontophoretic barrels allowed the ejection of drugs of low solubility in water, such as yohimbine and prazosin. (For the manufacture of these electrodes, see Haigler and Aghajanian, 1973; Crossman et al., 1974.) Irrespective of electrode assembly, signal to noise ratios were at least $4 / 1$; in those relatively few instances when action potentials from more than one sympathetic preganglionic neuron (SPN) were recorded simultaneously, the peak-topeak amplitude of the discharge of the SPN chosen to be characterized was greater than twice that of any other background activity.

All recording barrels were filled with a $1 \%$ solution of Fast Green in $2 \mathrm{M} \mathrm{NaCl}$ ( 6 to 11 megohms). Signals were amplified 1000-fold with an AC amplifier (bandpass, 200 to $4000 \mathrm{~Hz}$ and $60-\mathrm{Hz}$ notch filter). Spikes then were displayed on an oscilloscope and directed into an electronic counter which was reset automatically every 4,8 , or $16 \mathrm{sec}$. The output of the counter was fed into a chart recorder which generated the integrated rate histograms shown in Figures 3 and 4.

For iontophoresis, the following solutions were used at pH 3.5 to 4.5: $l$-NE bitartrate (0.1 M, Regis), $l$-epinephrine bitartrate $(0.1 \mathrm{~m}$, Regis), $l$ - $\alpha$-methyl-NE base $(0.1 \mathrm{M}, \mathrm{pH}$ 4 with tartaric acid, Sterling-Winthrop), $l$-phenylephrine $\mathrm{HCl}(0.1 \mathrm{M}$, Sigma), clonidine $\mathrm{HCl}(0.1$ or $0.02 \mathrm{M}$ in 0.16 M NaCl, gift from Rhône-Poulenc), yohimbine $\mathrm{HCl}(0.05$ $\mathbf{M}$, Aldrich), phentolamine mesylate $(0.1 \mathrm{M}$, gift from Ciba-Geigy), sotalol $\mathrm{HCl}$ (0.1 M, gift from Mead Johnson), prazosin $\mathrm{HCl}$ (1.5 mM, Pfizer), and GABA ( $\gamma$-aminobutyric acid, $0.2 \mathrm{M})$. Glutamate $(0.3$ or $0.1 \mathrm{M}$ in $0.1 \mathrm{M} \mathrm{NaCl})$ was prepared at $\mathrm{pH}$ 8.4. Automatic current balancing was in effect with five-barrel electrodes; balancing currents were passed through a side barrel filled with $4 \mathrm{M} \mathrm{NaCl}$ (20 to 40 megohms). The resistance of all drug-containing channels was 120 to 170 megohms in five-barrel electrodes and 70 to 150 megohms with six-barrel electrodes (except for yohimbine and prazosin which were delivered from 180- to 250-megohm channels). Retaining currents of appropriate polarity were used between ejections ( 6 to $8 \mathrm{nA}$ with five-barrel electrodes; 10 to $12 \mathrm{nA}$ with sixbarrel electrodes). All drugs were applied at regular intervals to insure the reproducibility of the drug ejections (Bradshaw and Szabadi, 1974).

Assessment of drug potency and drug antagonism. An index of the potency of inhibitory compounds was obtained using the protocol of DeMontigny and Aghajanian (1977) which is especially useful to compare the potencies of substances apt to produce $100 \%$ inhibition of cell firing.

For each drug application, the amount of charge necessary to decrease the discharge rate of the neuron under study by $50 \%$ within 20 to $60 \mathrm{sec}\left(Q_{50}\right.$ in nanocoulombs, nC) was determined by multiplying the iontophoretic current used ( $I$ in nanoamperes) by the time ( $T_{50}$ in seconds) necessary to achieve this $50 \%$ inhibition. Given two related agonists having an identical transport num- 
ber, the one with the lower $Q_{50}$ will be considered in a first approximation to be the most potent (the assumption of identical transport numbers is not unreasonable when comparing closely related compounds, such as catecholamine derivatives prepared in equimolar concentrations at identical $\mathrm{pH}$ ).

In the present study, increases in $Q_{50}$ values have been used as the most sensitive index of drug antagonism. Indeed, during the application of an antagonist, the $T_{50}$ for a given compound delivered at a constant current increases (Simmonds, 1974; Straughan, 1974) and only when the antagonism is of much larger magnitude does the agonist fail to produce $50 \%$ inhibition during the standard ejection time.

Stimulation of sympathetic preganglionic axons. Anatomical and electrophysiological studies in the pigeon (MacDonald and Cohen, 1970; Cabot and Cohen, 1977b, 1980; Cabot et al., 1979) have established that sympathetic preganglionic neurons (SPNs) in the initial three thoracic spinal segments (segments 15 to 17 in accordance with the terminology of Huber, 1936) give rise to axons which terminate and/or pass through the sympathetic paravertebral ganglion associated with the last cervical spinal segment (G14) (Fig. 1). In the present experiments, these axons were stimulated with a pair of bipolar, stainless steel (No. 00 insect pins) electrodes which were inserted directly into G14. The electrodes were epoxy-insulated to within 50 to $100 \mu \mathrm{m}$ of the tips. All experiments were done on the right side.

In order to eliminate any possibility of current spread to the adjacent ventral rootlets, G14 was isolated surgically. Following a dorsal midline incision, the muscles attached along the dorsal and transverse processes of the last cervical and initial four thoracic vertebrae were removed and the vertebral column was fixed in place with stainless steel plates (Cabot and Cohen, 1977a). A laminectomy was performed, exposing dorsal root ganglion 14, its rootlets, the ventral roots of this spinal segment, and G14. Subsequently, the dorsal and ventral roots were cut. Since G14 contains the majority of sympathetic cardiac postganglionic neurons (MacDonald and Cohen, 1970; Cabot and Cohen, 1977a), the placement of the stimulating electrodes was judged to be optimal if a stimulus train of 10 to 20 pulses $(0.5 \mathrm{msec}$ pulse duration, $25 \mathrm{~Hz}, 25$ to $50 \mu \mathrm{A}$ current intensity) elicited a marked, short latency cardioacceleration. Mechanical damage to preganglionic axons was apparently minimized by this placement as these axons exhibited low thresholds for activation with single, constant current pulses $(0.5 \mathrm{msec}$ duration, 25 to $150 \mu \mathrm{A}$ current intensity).

Identification of sympathetic preganglionic neurons. After the isolation of G14, a laminectomy was performed between the first and third thoracic spinal segments (T1 to T3). Since the avian thoracolumbar preganglionic cell

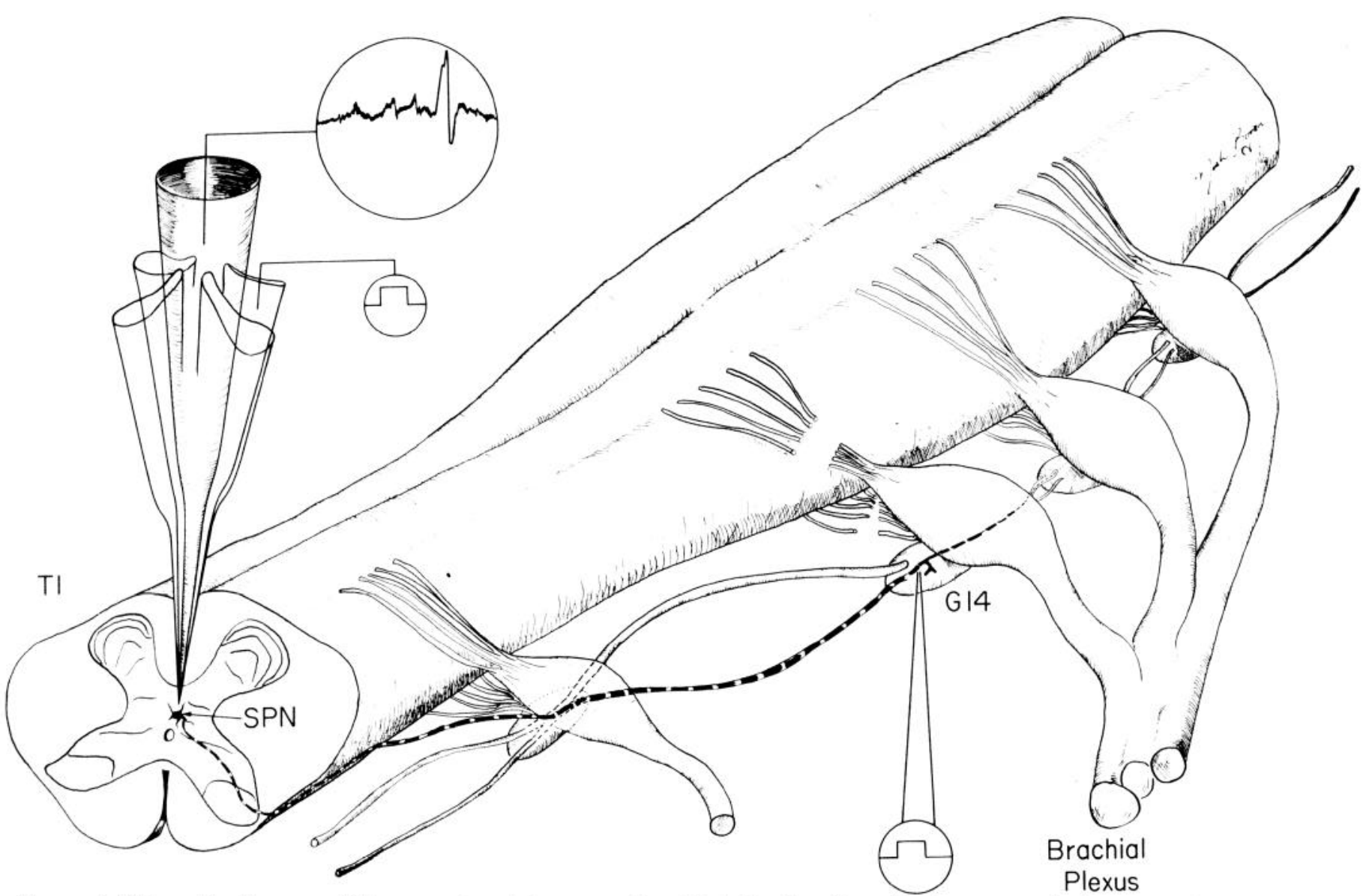

Figure 1. Schematic diagram of the experimental preparation. Note the location of avian sympathetic preganglionic neurons (SPNs) and the isolation of sympathetic ganglion 14 (G14). T1, first thoracic spinal segment. 
column (column of Terni) is located dorsal and dorsolateral to the central canal (Terni, 1923; MacDonald and Cohen, 1970; Cabot and Cohen, 1977b, 1980), the most effective trajectory for recording microelectrodes involved a dorsal midline approach. In order to do this, however, the blood sinus located on the dorsal surface of the spinal cord had to be cauterized carefully in the restricted region of $\mathrm{T} 1$ to $\mathrm{T} 3$ where recording was to begin. Additional areas were cauterized as necessary in any given experiment. After the local removal of the blood sinus, small openings in the dural and pial membranes were made with a 26 gauge needle. The above protocol often resulted in the minor herniation of the dorsal funiculus (right side only). The exposed spinal cord and G14 were covered with a warmed mixture of mineral oil and petroleum jelly $\left(41^{\circ} \mathrm{C}\right)$.

Electrophysiological criteria for the identification of SPNs included (i) constancy of antidromic activation latency and (ii) the collision of an orthodromically conducted action potential with that of an antidromically elicited action potential (Darian-Smith et al., 1963). Both criteria were satisfied for every cell reported in this study prior to any evaluation of their pharmacological sensitivity to iontophoretically applied drugs.

The recording electrode barrel in all experiments contained a $2 \mathrm{~m} \mathrm{NaCl}, 1 \%$ Fast Green solution. In four experiments spaced throughout the total series of 20, a Fast Green dye spot was deposited at the recording site of a SPN which had been characterized pharmacologically (DC cathodal current, $20 \mu \mathrm{A}, 20 \mathrm{~min}$ duration). At the end of these experiments, the birds were perfused with $10 \%$ formalin and the spinal cord segment containing the recording site was removed. Serial $30-\mu \mathrm{m}$ sections were cut frozen, mounted on slides, air dried, and counterstained with cresyl violet acetate.

\section{Results}

Identification and general properties of SPNs. Avian SPNs are localized dorsal and dorsolateral to the central canal at T1 to T3 spinal levels. It should be appreciated that, despite this midline locus, the preganglionic cell column is a paired nucleus and all of the available evidence shows that there are no cross-projections. As noted under "Materials and Methods," cells were identified as being SPNs if $(i)$ the onset latency of an antidromically evoked discharge remained constant at threshold ( $\mathrm{T}$ ) and $2 \times \mathrm{T}$ current intensities for activation and (ii) the requirements of the collision test were satisfied (Fig. 2). SPNs meeting these criteria were found exclusively to the right of and within $150 \mu \mathrm{m}$ of the midline (i.e., ipsilateral to the site of preganglionic axon stimulation), at depths of approximately 500 to $1000 \mu \mathrm{m}$ from the dorsal surface of the spinal cord, and throughout T1, T2, and rostral T3 spinal segments, though most of the recordings were from cells localized within caudal T1 and rostral T2. Additionally, in the four experiments in which Fast Green was deposited at the recording site of a SPN, histological recovery of the dye spots revealed that all such marks were to the right of the midline and within the cytoarchitectonically defined boundaries of the sympathetic preganglionic cell column.

Generally, the conformation of the extracellularly re-

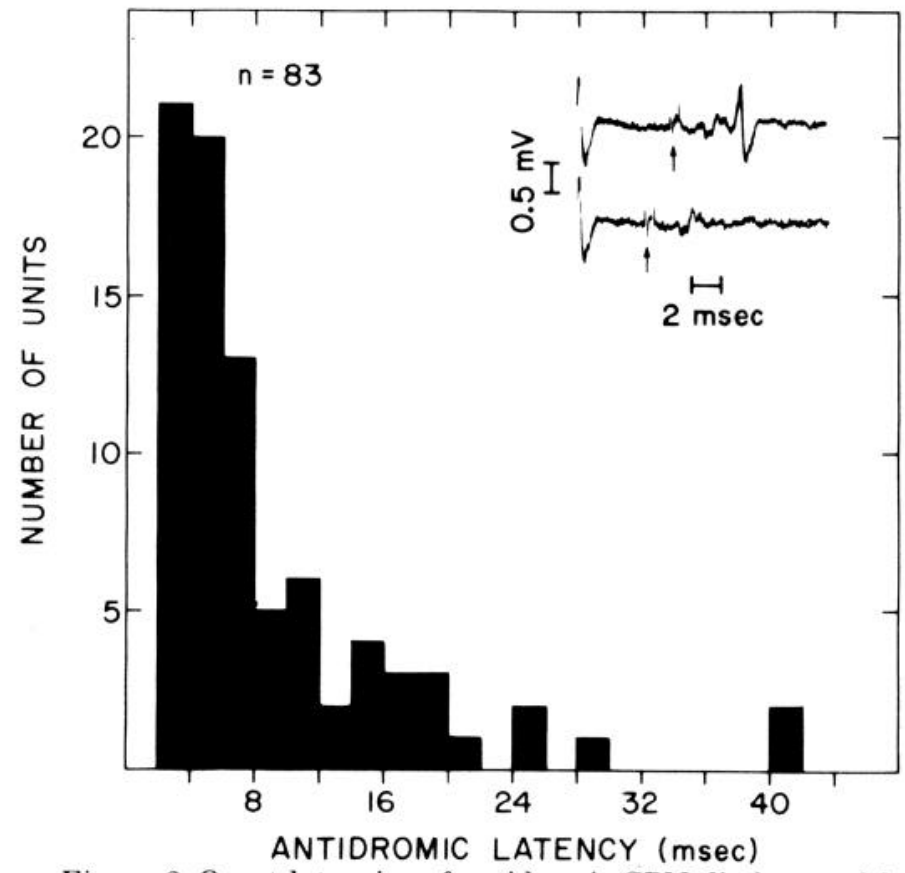

Figure 2. Onset latencies of antidromic SPN discharges following stimulation of G14. Inset, Collision of a spontaneous SPN discharge with an antidromically evoked discharge. Each oscilloscope trace is triggered by the spontaneous firing of a SPN. If the antidromic stimulus (arrow) is delayed by greater than $6 \mathrm{msec}$, then antidromic invasion occurs (upper trace). If the stimulus is delayed by less than $6 \mathrm{msec}$, then collision occurs (lower trace). Each trace represents the superimposition of two oscilloscope sweeps.

corded action potentials of SPNs differed depending upon the electrode assembly used. In experiments where five-barrel electrodes were utilized, the potentials were predominantly biphasic, negative-positive; small preceding- and/or after-positivities were noted sometimes. The extracellular potentials recorded with six-barrel electrodes were usually triphasic, positive-negative-positive; frequently a prominent after-positivity was present as well. The observed peak-to-peak amplitude voltage ranged from 0.4 to $0.6 \mathrm{mV}$ with five-barrel electrodes and from 0.5 to $5.0 \mathrm{mV}$ with six-barrel electrodes. Regardless of the electrode assembly used, stable recordings for periods of 15 to $30 \mathrm{~min}$ were common. However, the use of six-barrel electrodes allowed longer term observations and often the discharge of a SPN could be isolated for 1 to $2 \mathrm{hr}$.

By requiring that the collision test be satisfied for all neurons, the present sample is biased toward that minority of SPNs showing maintained activity. While the actual number of cells without spontaneous activity was not tabulated systemically, a conservative estimate would be that over $80 \%$ of the SPNs at T1 to T3 spinal levels are silent under the present experimental conditions. The sample is biased in yet another way; SPNs with irregular discharge rates of less than 0.5 spike/sec were encountered sometimes but were not characterized pharmacologically because of difficulties experienced in establishing reliable base line levels of activity.

Given these limitations, the SPNs studied exhibited onset latencies of antidromic activation ranging from 2 
to $43 \mathrm{msec}$ (Fig. 2). These latencies suggest that avian preganglionic axons conduct at 0.4 to 5.6 meters/sec (the distances between the stimulating and recording electrodes were estimated to be 7 to $15 \mathrm{~mm}$ ). This conduction velocity range compares well with previous estimates in the pigeon (Cabot and Cohen, 1980) and is similar to that reported in mammals (Fernandez de Molina et al., 1965; Polosa, 1967; Taylor and Gebber, 1973; McLachlan and Hirst, 1980). The average antidromic activation latency was $9.5 \pm 7.8$ msec (mean $\pm \mathrm{SD}, n=83$ cells); the median latency was $6.5 \mathrm{msec}$. There were no systematic differences associated with the type of recording electrode assembly.

The maintained activity of SPNs ranged from 0.1 to 13.0 spikes/sec. The average firing frequency was $3.2 \pm$ 2.6 spikes/sec ( $n=73$ cells); the median activity was 2.7 spikes/sec. Again, there were no significant differences associated with the type of electrode assembly used. Moreover, there was no apparent correlation between discharge rate and the onset latency for antidromic activation.

Inhibitory effects of clonidine and catecholamines on SPN single unit activity. Clonidine, $\alpha$-methyl-NE, epinephrine, $\mathrm{NF}$, and phenylephrine inhibited the firing rate of all SPNs tested irrespective of the type of iontophoretic electrode used (Figs. 3 and 4 and Table I). The cells responded to iontophoretic currents of increasing intensity first by an increase in the maximum level of inhibition, which eventually reached $100 \%$ with the vast majority of the cells, and secondly by shortening the time necessary to achieve $100 \%$ inhibition (Fig. $3 B$ ). The amplitude and shape of the action potentials were usually unaltered by either clonidine or catecholamines although, occasionally, a slight amplitude increase was observed during the period of application and during the recovery phase. During periods of total inhibition, no change either in the latency, size, and shape of antidromically elicited spikes or in the threshold currents necessary to elicit these discharges was noted (a slight increase in the amplitude of antidromic spikes was observed again). The inhibition of cell discharges caused by the iontophoretic applications of clonidine and catecholamines was fully reversible and unaltered with repeated applications (up to 20 times in the case of NE, up to 6 times in the case of clonidine). Recovery from the inhibitory effect of catecholamines was moderately rapid (12 to $40 \mathrm{sec}$, Fig. $3, A$ to $F$ ) while that from clonidine was invariably slow ( 2 to $10 \mathrm{~min}$, Figs. $3 D$ and $4, A$ to $C$ ). The inhibition resulting from the delivery of comparable currents of GABA completely recovered within 4 to $8 \mathrm{sec}$ following the end of the drug application (Fig. $3 A$ ). These observations were consistent independent of the electrode assembly used. A description of the number of cells sampled, iontophoretic currents, and ejections times used is presented in summary form in Table I.

The amount of charge necessary to decrease the neuronal firing rate by $50 \%\left(Q_{50}=T_{50} \times I ; I\right.$ in nanoamperes, $T_{50}$ in seconds, $Q$ in nanocoulombs) was reproducible across pipettes and cells and characteristic of a particular amine when determined with the same type of electrode (five- or six-barrel). The $Q_{50}$ values determined with sixbarrel electrodes were larger and more variable than those measured with five-barrel electrodes; this certainly can be attributed to the geometry of the six-barrel electrodes and the fact that, in these electrodes, the iontophoretic barrels were further away from the recording electrode (25 to $10 \mu \mathrm{m}$ ). Clonidine was applied using either a standard $0.1 \mathrm{M}$ solution or a $20 \mathrm{~mm}$ solution diluted in $160 \mathrm{~mm} \mathrm{NaCl}$; the dilution of the drug resulted in an approximately 3 -fold increase in the corresponding $Q_{50}$ values. As indicated in Table I, the $Q_{50}$ values for clonidine and catecholamines as determined with five-

\section{TABLE I}

Effect of iontophoretically applied clonidine and catecholamines on the discharge rate of SPNS

All inhibitory compounds were applied with currents of appropriate intensity to produce 80 to $100 \%$ inhibition of cell firing within the period of ejection. The quantity of charge $\left(Q_{50}\right)$ required to decrease the cell firing by $50 \%$ (see "Materials and Methods") was determined for each inhibitory compound and was averaged across cells. $Q_{50}$ values were obtained using 2 to 16 different electrodes.

\begin{tabular}{|c|c|c|c|c|c|c|c|}
\hline Drug & Electrode Type & Current & Ejection Time & Effect & $\begin{array}{c}Q_{50}{ }^{\circ} \\
\text { Mean } \pm \mathrm{SD}\end{array}$ & $\begin{array}{l}\text { Total } \\
\text { Sample }\end{array}$ & $\begin{array}{c}\text { No. of Cells } \\
\text { Affected }\end{array}$ \\
\hline & & $n A$ & sec & & & & \\
\hline Clonidine, $0.02 \mathrm{M}^{b}$ & 5-barrel & $6-20$ & $30-80$ & Inhibitory & $270 \pm 210$ & 10 & 10 \\
\hline Clonidine, $0.1 \mathbf{~ M}^{b}$ & 5-barrel & $2-6$ & $40-70$ & Inhibitory & $92 \pm 24$ & 4 & 4 \\
\hline$\alpha$-Methylnorepinephrine & 5-barrel & $3-15$ & $20-50$ & Inhibitory & $124 \pm 47$ & 6 & 6 \\
\hline Epinephrine & 5-barrel & $4-15$ & $20-50$ & Inhibitory & $172 \pm 57$ & 6 & 6 \\
\hline Norepinephrine & 5-barrel & $5-20$ & $30-60$ & Inhibitory & $379 \pm 223$ & 17 & 17 \\
\hline Glutamate & 5 -barrel & $1-30$ & $0-30$ & Excitatory & & 9 & 9 \\
\hline Clonidine, $0.02 \mathrm{M}^{b}$ & 6-barrel & $15-60$ & $40-80$ & Inhibitory & $1340 \pm 2000$ & 19 & 19 \\
\hline$\alpha$-Methylnorepinephrine & 6-barrel & $10-40$ & $40-80$ & Inhibitory & $542 \pm 369$ & 6 & 6 \\
\hline Epinephrine & 6 -barrel & $15-50$ & $40-80$ & Inhibitory & $636 \pm 348$ & 5 & 5 \\
\hline Norepinephrine & 6-barrel & $15-70$ & $40-80$ & Inhibitory & $719 \pm 862$ & 32 & 32 \\
\hline Phenylephrine & 6-barrel & $50-100$ & $40-120$ & Inhibitory & $4990 \pm 2850$ & 4 & 4 \\
\hline $\mathrm{G} \wedge \mathrm{B} \Lambda$ & 6-barrel & $30-60$ & $16-40$ & Inhibitory & $497 \pm 319$ & 6 & 6 \\
\hline
\end{tabular}

\footnotetext{
${ }^{a}$ Statistical analyses of the data were made using the two-tailed Student's $t$ test. The results were: $0.1 \mathrm{~m}$ clonidine and $\alpha$-methylnorepinephrine, not significant; $0.1 \mathrm{M}$ clonidine and epinephrine, $p<0.01 ; 0.1 \mathrm{M}$ clonidine and norepinephrine, $p<0.0005 ; \alpha-$ methylnorepinephrine and epinephrine, not significant; $\alpha$-methylnorepinephrine and norepinephrine, $p<0.0005$; epinephrine and norepinephrine, $p<0.0025$; phenylephrine and $\alpha$ methylnorepinephrine, norepinephrine, or epinephrine, $p<0.01$ using six-barrel electrodes.

${ }^{b}$ Note that clonidine was used in two different concentrations for iontophoresis, a standard $0.1 \mathrm{~m}$ solution, $\mathrm{pH} 4$, and a $0.02 \mathrm{M}$ solution, $\mathrm{pH} 4$, diluted with $160 \mathrm{~mm} \mathrm{NaCl}$.
} 
barrel electrodes using standard $0.1 \mathrm{~m}$ drug solutions at $\mathrm{pH} 4.0$ were in the following rank order: clonidine $>\alpha$ methyl-NE $>\mathrm{E}>\mathrm{NE}$. With six-barrel electrodes, the rank order was $\alpha$-methyl-NE $>\mathrm{E}>\mathrm{NE}>$ phenylephrine. In this latter case, only the $Q_{50}$ for phenylephrine was statistically different from the others. $Q_{50}$ values for clonidine could not be compared directly in this last case since the drug was ejected from a solution containing 160 mM sodium ions.

Among the 83 cells presented in this study, 9 were initially silent and the effects of NE ( 6 cells) and clonidine ( 3 cells) were tested while the neurons were made to discharge at a constant slow rate ( 1.5 to 3 spikes/sec) by continually applying very small currents of glutamate $(0$ $\mathrm{nA}$ or leak to $12 \mathrm{nA}$ ). The effects of NE and clonidine on the cells' firing rate were quantitatively identical to that observed in the case of spontaneously active neurons and, therefore, the data were combined in Table I.

A number of silent units also were encountered which could be activated transiently by ejecting rather large currents of glutamate (50 nA and up). These units could not be made to fire continuously at a regular rate. A fraction of them underwent what could be interpreted as a depolarizing block (decrease in spike size leading to absence of spike), while others rapidly became unresponsive to glutamate. Such units were not included in the present sample of 83 cells.

Effects of adrenergic receptor antagonists on the inhibitory effects of clonidine and norepinephrine. All but two (antagonism of clonidine by piperoxan) of these experiments were made using six-barrel micropipettes because five-barrel electrodes were found unsatisfactory
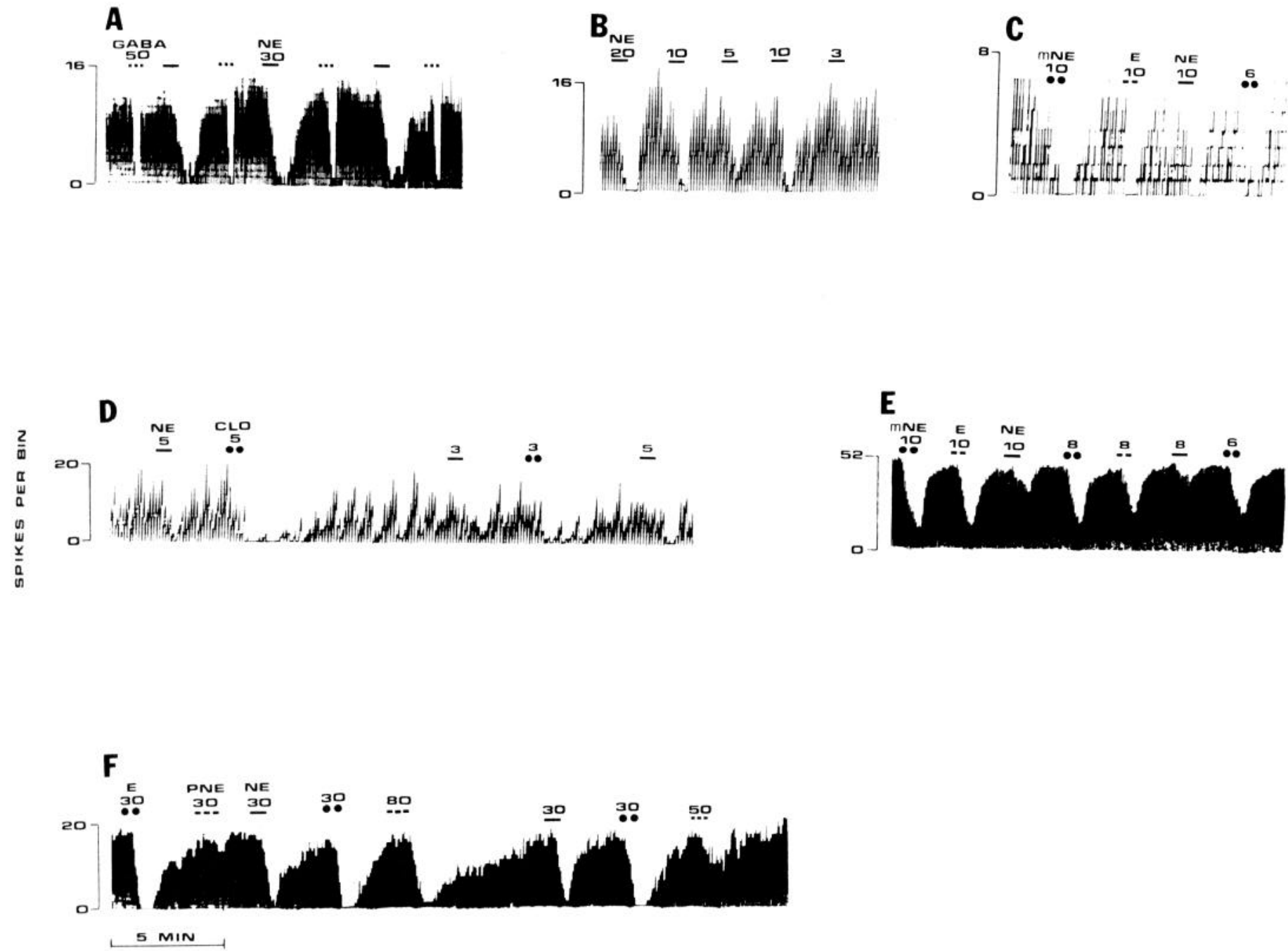

Figure 3. Inhibition of sympathetic preganglionic neuronal discharge by iontophoretic applications of clonidine and various catecholamines. Integrated rate histograms illustrating the effect of clonidine and catecholamines on SPN discharge. Panel $A$ shows the differences between the recovery pattern from GABA- and NE-induced inhibition. Panel $B$ illustrates the dose dependency of the effects of NE. Panels $C$ to $F$ demonstrate inhibition of SPN-maintained activity with the application of several catecholamines and clonidine. Recordings were obtained with five-barrel $(B, C, D$, and $E)$ or six-barrel electrodes $(A$ and $F)$. The duration of iontophoretic applications is indicated by the horizontal solid or dotted lines above the histograms (40 or 50 sec); the associated numbers represent the current applied in nanoamperes. Bin width: $4 \mathrm{sec}$ in panels $A, E$, and $F$; $8 \mathrm{sec}$ in panels $B, C$, and $D$. CLO, clonidine; $E$, epinephrine; $G A B A, \gamma$-aminobutyric acid; $N E$, norepinephrine; $m N E$, $\alpha$-methylnorepinephrine; $P N E$, phenylephrine. 

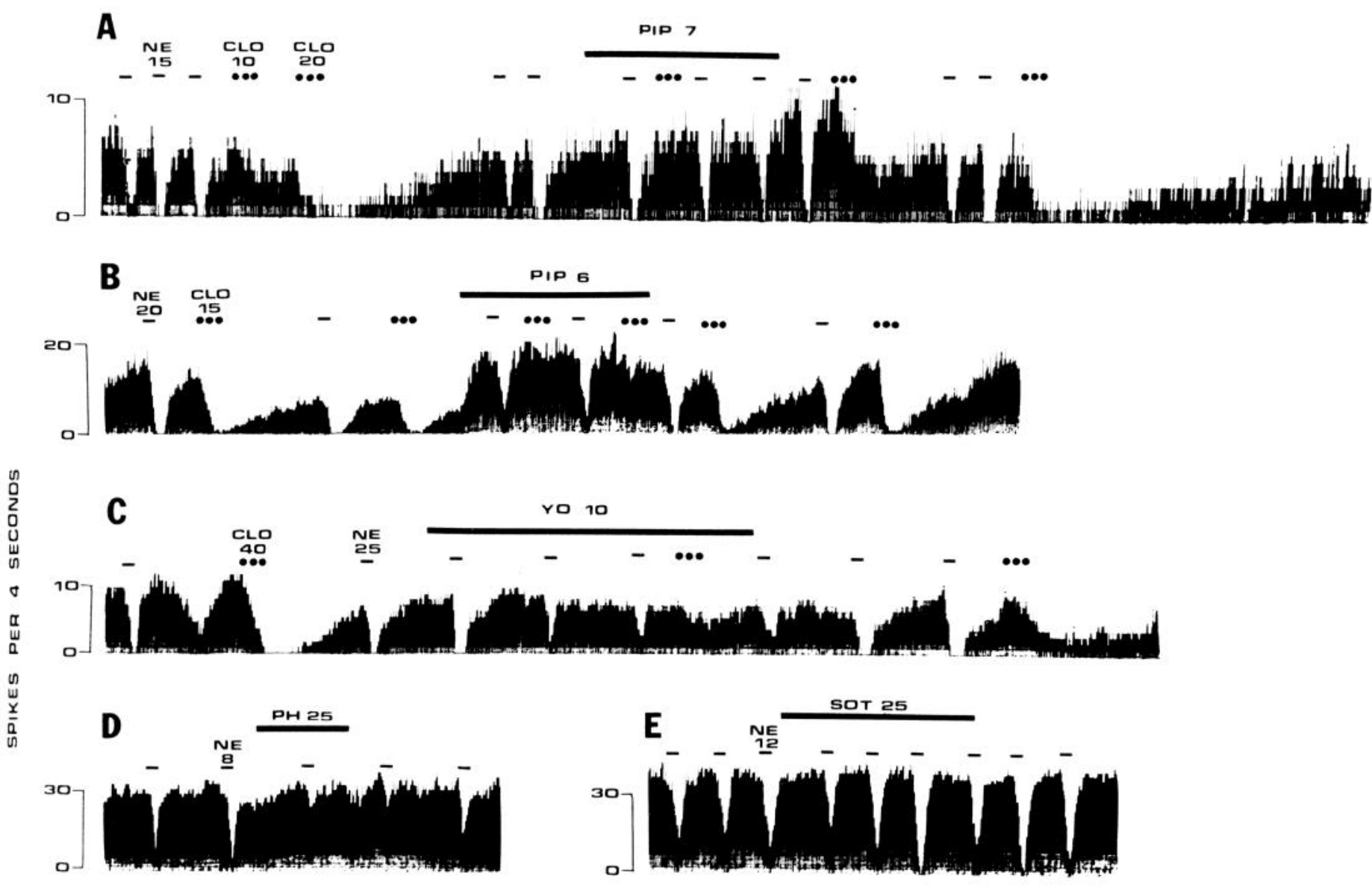

$$
5 \text { MiN }
$$

Figure 4. Pharmacological characterization of the receptor-mediated inhibition of sympathetic preganglionic neuronal discharge following iontophoresis of $\mathrm{NE}$ and clonidine. Panels $A$ to $D$, Integrated rate histograms (bin width, 4 sec) illustrating the antagonism of norepinephrine $(N E)$ - and clonidine $(C L O)$-induced inhibition of spontaneous preganglionic cell discharges by the $\alpha$ antagonists, piperoxan $(P I P)$, yohimbine $(Y O)$, and phentolamine $(P H)$. Panel $E$, Integrated rate histogram demonstrating the lack of antagonism by the $\beta$ antagonist, sotalol (SOT), of the inhibitory effect of NE. The duration of iontophoretic current applications is indicated by the horizontal solid or dotted lines above the histograms; the associated numbers represent the currents applied in nanoamperes. All of the data in the figure were obtained with six-barrel electrodes.

to eject reliably drugs of low solubility in water, such as yohimbine and prazosin.

The $\alpha_{2}$ antagonists, piperoxan (6 to $15 \mathrm{nA}, 10$ to 20 $\mathrm{min}$ ) and yohimbine (10 to $25 \mathrm{nA}, 10$ to $20 \mathrm{~min}$ ), increased significantly and reversibly the $Q_{50}$ values for the inhibition of SPN activity by NE (Fig. 4, $A, B$, and $C$ and Table II). Neither piperoxan nor yohimbine had any action on the inhibitory effects of GABA ( 3 cells tested with each antagonist). The broad spectrum $\alpha$ antagonist, phentolamine ( 13 to $25 \mathrm{nA}, 15 \mathrm{~min}$ ), also antagonized the inhibitory effect of NE in all 6 cells tested (Fig. $4 D$ ). However, in 5 out of the 6 cells, the antagonism by phentolamine was less marked than in the example shown in Figure 4. Moreover, signs of local anesthetic effects (spike broadening, decrease in amplitude, dissociation of presumed initial segment, and somadendritic components) were noted in four cases after $10 \mathrm{~min}$ of iontophoretic phentolamine.

The $\beta$ antagonist, sotalol ( $25 \mathrm{nA}$, up to $20 \mathrm{~min}$, 4 cells tested; Fig. $4 E$ ), and the $\alpha_{1}$ antagonist, prazosin ( $30 \mathrm{nA}$, up to $20 \mathrm{~min}, 5$ cells tested), failed to produce any detectable change in the $Q_{50}$ values for NE. These two compounds did not produce any local anesthetic effects in the doses used.

Yohimbine ( 10 to $25 \mathrm{nA}, 10$ to $20 \mathrm{~min}, 5$ cells) and piperoxan ( 6 to $15 \mathrm{nA}, 10$ to $20 \mathrm{~min}, 4$ cells) antagonized the inhibitory effect of clonidine (Fig. 4, $A, B$, and $C$ ). Both compounds also could restore the firing rate of a neuron inhibited by a prior application of clonidine (Fig. $4 B$ ). Piperoxan appeared to antagonize more completely the inhibitory effect of clonidine than that of NE in all 3 cells where antagonism to both compounds could be tested simultaneously (Fig. $4, A$ and $B$ ) and the same result was observed with yohimbine in 3 cells (Fig. $4 C$ ). It should be noted, however, that strictly equiefficacious doses of $\mathrm{NE}$ and clonidine may not have been delivered in these instances.

Finally, in 4 cells, NE also was applied during the recovery phase from a prior clonidine application to determine whether the latter compound might antagonize the inhibitory effect of NE and thus exhibit properties of a partial antagonist. No indication of a decreased 
TABLE II

Antagonism of NE-induced inhibition of SPN discharge rate by $\alpha$-adrenergic receptor antagonists

$\mathrm{NE}$ was applied iontophoretically (15 to $50 \mathrm{nA}, 40$ to $60 \mathrm{sec}$ ) at regular intervals in the absence or presence of a concomitant ejection of antagonist (10- to 20-min application using the currents shown above). All control ejections of NE resulted in 80 to $100 \%$ inthibition of cell firing. $Q_{50}$ values were determined during the pre-drug period by averaging measurements obtained from two to three consecutive responses and again toward the end of the application of the antagonist.

\begin{tabular}{|c|c|c|c|c|c|}
\hline \multirow{2}{*}{$\begin{array}{l}\text { Cell } \\
\text { No. }\end{array}$} & \multirow[b]{2}{*}{ Antagonist } & \multirow{2}{*}{$\begin{array}{l}\text { Iontophoretic } \\
\text { Current }\end{array}$} & \multicolumn{3}{|c|}{$Q_{50}$ for NE Inhibition } \\
\hline & & & Pre-drug & $\begin{array}{l}\text { During } \\
\text { Drug }\end{array}$ & $\begin{array}{l}\text { Percentage } \\
\text { of Control }\end{array}$ \\
\hline & & $n A$ & & & \\
\hline 1 & Yohimbine & 10 & 600 & 1500 & 250 \\
\hline 2 & Yohimbine & 13 & 1400 & $>2800^{a}$ & $>200^{a}$ \\
\hline 3 & Yohimbine & 14 & 480 & 720 & 150 \\
\hline 3 & Yohimbine & 20 & 480 & 900 & 188 \\
\hline 4 & Yohimbine & 20 & 400 & 720 & 180 \\
\hline 5 & Yohimbine & 25 & 720 & $>1440^{a}$ & $>200^{a}$ \\
\hline 6 & Yohimbine & 25 & 420 & 1680 & 400 \\
\hline 7 & Piperoxan & 5 & 480 & 720 & 150 \\
\hline 8 & Piperoxan & 6 & 780 & 1680 & 215 \\
\hline 9 & Piperoxan & 7 & 112 & 224 & 200 \\
\hline 10 & Piperoxan & 8 & 575 & 1008 & 175 \\
\hline 11 & Piperoxan & 10 & 448 & $864^{\alpha}$ & 193 \\
\hline 12 & Piperoxan & 13 & 448 & $>2000^{a}$ & $>446^{a}$ \\
\hline 13 & Piperoxan & 15 & 500 & $>2000^{a}$ & $>400$ \\
\hline 14 & Phentolamine & 13 & 300 & $>600^{a}$ & $>200^{a}$ \\
\hline 15 & Phentolamine & 25 & 400 & 720 & 180 \\
\hline 16 & Phentolamine & 25 & 180 & 300 & 167 \\
\hline 17 & Phentolamine & 25 & 400 & $>600^{a}$ & $>150^{a}$ \\
\hline 18 & Phentolamine & 25 & 216 & $>360^{a}$ & $>167^{a}$ \\
\hline 19 & Phentolamine & 25 & 132 & 192 & 145 \\
\hline
\end{tabular}

${ }^{a}$ In these cases, the agonist failed to produce $50 \%$ inhibition of the cell's discharge rate by the end of the standard ejection time in the presence of the antagonists.

effect of NE was found in any of these cases (Fig. 4, B and $C$ ).

\section{Discussion}

The results of the present study indicate that iontophoretically applied catecholamines and clonidine uniformly inhibit the spontaneous firing of SPNs. Thus, in agreement with several previous authors (DeGroat and Ryall, 1967; Coote and MacLeod, 1977; Hongo and Ryall, 1966), it seems reasonable to conclude that at least one of the physiological effects of endogenously released catecholamines within the SPN neuropil is to inhibit the discharge rate of SPNs.

The usefulness of the $Q_{50}$ values as an index of drug potency, as well as their validity to evaluate drug antagonism, has been documented previously in various iontophoretic studies (Simmonds, 1974; Wang et al., 1979). $Q_{50}$ values can be used to determine the rank order of potency of several agonists only if the transport number for these agents is identical. In the case of equimolar solutions of chemically related drugs, such as the various catecholamines used in this study, the hypothesis of identical transport numbers can be reasonably assumed. From the respective $Q_{50}$ values of $\alpha$-methyl-NE, E, and NE determined with five-barrel electrodes (Table I), it can be suggested, therefore, that the relative potency of these compounds lies in the above order. The fact that $\alpha$-methyl-NE is significantly more potent than NE is of potential interest as it provides supporting evidence for an often proposed but unverified hypothesis regarding the mechanism of the central antihypertensive action of $\alpha$-methyldopa (Langer et al., 1980). It is amply documented that this centrally active drug has to be converted by noradrenergic or adrenergic terminals into $\alpha$-methyl$\mathrm{NE}$ or $\alpha$-methylepinephrine in order to exert its hypotensive action (Henning and Rubenson, 1971; Van Zwieten, 1980). Therefore, these two catecholamines were supposed to act as false neurotransmitters. The present data suggest that the antihypertensive action of $\alpha$-methyldopa could be explained in part by the fact that $\alpha$-methyl-NE is released at the level of the SPNs in place of NE but produces an inhibition of these neurons in excess of that resulting from the release of the physiological transmitter.

As indicated in Table I (five-barrel electrodes), the $Q_{50}$ values for clonidine-induced inhibition were lower than those for all of the catecholamines tested when the antihypertensive drug was used in equimolar concentration with that of the amines. Again, given the assumption of equal transport numbers, this result suggests that clonidine may be more potent than norepinephrine or epinephrine in inhibiting the discharge rate of SPNs. When a solution of clonidine in $\mathrm{NaCl}$ was used for iontophoresis, the observed $Q_{50}$ values for inhibition were increased substantially as might be expected from a reduction in the transport number of the active compound. Recovery from clonidine-induced inhibition was extremely slow in comparison to that following applications of catecholamines. This fact can probably be accounted for by differences in uptake and catabolism.

The determination of the relative potencies of pharmacological agents using six-barrel electrodes was inconclusive. Indeed, the differences in $Q_{50}$ values between clonidine, $\alpha$-methyl-NE, E, and NE that were clearly apparent with five-barrel electrodes were not evident when averaged across pipettes; this is due in large part to an increased dispersion of the observed $Q_{50}$ values but perhaps also to the fact that the potency of the drug may play a somewhat reduced role in the kinetics of the cell response when the active compound is delivered 30 to 40 $\mu \mathrm{m}$ away from the cell body. In this situation, other factors, such as diffusion, binding, uptake, and liposolubility, may become significant in determining how fast the cell is inhibited unless very large differences in potency or efficacy exist. Such an important difference in potency was demonstrated in the case of phenylephrine when compared with other catecholamines (Table I). In summary, the weights of the combined evidence lead to the proposal that the relative order of potency for clonidine and all of the other amines tested in the present study was: clonidine $>\alpha$-methyl-NE $>\mathrm{E}>\mathrm{NE} \gg$ phenylephrine.

This rank order suggests the possibility that an $\alpha_{2}$ receptor may be involved in mediating the effect of catecholamines. However, because of the difficulties associated with the determination of relative potencies using the technique of iontophoresis, the most pertinent discussion of the present findings derives from comparing 
the data with those obtained elsewhere in the CNS with identical techniques for drug delivery. It then becomes apparent that the relative order of potency for clonidine and catecholamines found in the present study is identical with that found with the same techniques in the rat locus coeruleus (an $\alpha_{2}$-like adrenergic inhibition; Cedarbaum and Aghajanian, 1977) but is entirely different from that obtained at the level of the rat lateral geniculate ( $\alpha_{1}$-like adrenergic excitation; Rogawski and Aghajanian, 1980).

The hypothesis that an $\alpha_{2}$-like receptor may be involved in the inhibitory effect of both catecholamines and clonidine on the activity of SPNs is further supported by the effect of adrenergic antagonists on this response. Indeed, the only antagonists found to decrease significantly the inhibitory effects of NE and clonidine in the present study were the $\alpha$ antagonists, yohimbine, piperoxan, and phentolamine. Since the specific $\alpha_{1}$ antagonist, prazosin, was inactive, the effectiveness of yohimbine and piperoxan presumably can be attributed to their $\alpha_{2}$ antagonist properties.

A final distinguishing feature between $\alpha_{1}$ and $\alpha_{2}$ receptors, both centrally (Rogawski and Aghajanian, 1980; Cedarbaum and Aghajanian, 1977) and peripherally (Ruffolo et al., 1979), is that clonidine behaves as a full agonist at $\alpha_{2}$ receptors and as a partial agonist with low efficacy at $\alpha_{1}$ receptors. At the level of the SPNs, clonidine apparently behaved as a full agonist, again completely analogous to its action on the $\alpha_{2}$-like adrenergic receptors of the locus coeruleus and contrary to its action in the lateral geniculate nucleus ( $\alpha_{1}$ receptors).

Yohimbine and piperoxan appeared to antagonize more completely the clonidine-induced inhibitions of SPN discharges than those produced by NE. This observation, therefore, could suggest the possibility that clonidine and NE might be interacting with related but distinct receptor subtypes; indeed, a similar hypothesis has been proposed recently by Pelayo et al. (1980) to explain certain differences between the actions of clonidine and $\alpha$-methyl-NE on $\alpha_{2}$ receptors located presynaptically on peripheral noradrenergic neurons. Since the preganglionic cell column receives both an adrenergic and a noradrenergic input, the presence of a heterogeneous population of adrenergic receptors to match these two inputs might be expected. However, in the present experiments, the greater antagonistic effect of piperoxan and yohimbine against clonidine versus NE-induced inhibitions could merely result from the fact that the two agonists were not delivered in equiefficacious doses. Therefore, it is concluded that the present data can be accounted for satisfactorily at this stage by the existence of only one type of receptor related to the $\alpha_{2}$ subclass.

Clonidine has been shown previously to exert its sympathoinhibitory action in part at a spinal level (Hauesler, 1974; for reviews, see Kobinger, 1978; Laubie and Schmitt, 1977). The possibility of a direct action of the drug at the level of the preganglionic cell column in the cat has been suggested by Franz et al. (1978) and Madsen et al. (1980) although additional spinal sites may also exist (Dembrowsky et al., 1980). The present experiments support the conclusion of Franz et al. (1978) that clonidine is acting directly at the level of the sympathetic cell column. The location of the $\alpha_{2}$ receptors involved cannot. be determined from the present iontophoretic experiments, but an exclusively presynaptic location of these receptors on catecholaminergic nerve endings is not supported by the present evidence. These receptors, therefore, could be present either on some non-catecholaminergic element presynaptic to the SPNs (excitatory medullary input or spinal interneuron) or on the neurolemma of SPNs themselves. This last hypothesis is supported by reports of numerous synaptic contacts between terminals containing dense core vesicles and SPNs in various species including birds (Smolen and Ross, 1978; Chung et al., 1980; J. B. Cabot, unpublished data). Whether the $\alpha_{2}$ receptors described in the present study mediate the synaptic effects of noradrenaline, epinephrine, or both and whether other types of adrenergic receptors also are present in the preganglionic cell column remains to be determined.

\section{References}

Bradshaw, C. M., and E. Szabadi (1974) The measurement of dose in microelectrophoresis experiments. Neuropharmacology 13: 407-415.

Cabot, J. B., and D. H. Cohen (1977a) Avian sympathetic cardiac fibers and their cells of origin: Anatomical and electrophysiological characteristics. Brain Res. 131: 73-87.

Cabot, J. B., and D. H. Cohen (1977b) Anatomical and physiological characterization of avian sympathetic cardiac afferents. Brain Res. 131: 89-101.

Cabot, J. B., and D. H. Cohen (1980) Neural control of the avian heart. In Heart and Heart-like Organs, G. Bourne, ed., Vol. 1., pp. 199-258, Academic Press, New York.

Cabot, J. B., J. M. Wild, and D. H. Cohen (1979) Raphe inhibition of sympathetic preganglionic neurons. Science 203: 184-186.

Caserta, M., and L. L. Ross (1978) Biochemical and morpholog ical studies of synaptogenesis in the avian sympathetic cell column. Brain Res. 144: 241-255.

Cedarbaum, J. M., and G. K. Aghajanian (1977) Catecholamine receptors in locus coeruleus neurons: Pharmacological characterization. Eur. J. Pharmacol. 44: 375-385.

Chalmers, J. P. (1975) Brain amines and models of experimental hypertension. Circ. Res. 36: 469-480.

Chung, K., F. W. LaVelle, and R. D. Wurster (1980) Ultrastructure of HRP-identified sympathetic preganglionic neurons in cats. J. Comp. Neurol. 190: 147-155.

Coote, J. H., and V. H. MacLeod (1974) The influence of bulbospinal monoaminergic pathways on sympathetic nerve activity. J. Physiol. (Lond.) 241: 453-475.

Coote, J.H., and V. H. MacLeod (1977) The effect of intraspinal microinjections of 6-hydroxydopamine on the inhibitory influence exerted on spinal sympathetic activity by baroreceptors. Pfluegers Arch. 371: 277.

Crossmann, A. R., R. J. Walker, and G. N. Woodruff (1974) Problems associated with iontophoretic studies in the caudate nucleus and substantia nigra. Neuropharmacology 13: $547-552$

Dahlstrom, A., and K. Fuxe (1965) Evidence for the existence of monoamine-containing neurons in the central nervous system. II. Experimentally-induced changes in the intraneuronal amine levels of bulbospinal neuron systems. Acta Physiol. Scand. Suppl. 247, 64: 1-36.

Darian-Smith, I., G. Phillips, and R. D. Ryan (1963) Functional organization in the trigeminal main sensory and rostral spinal nuclei of the cat. J. Physiol. (Lond.) 168: 129-146.

DeGroat, W. C., and R. W. Ryall (1967) An excitatory action of 5 -hydroxytryptamine on sympathetic preganglionic neurons. Exp. Brain Res. 3: 299-305. 
Dembrowsky, K., J. Czachurski, K. Amendt, and H. Seller (1980) Tonic descending inhibition of the spinal-sympathetic reflex from the lower brain stem. J. Autonom. Nerv. Syst. 2: 157-182.

DeMontigny, C., and G. K. Aghajanian (1977) Preferential action of 5-methoxytryptamine and 5-methoxydimethyltryptamine on presynaptic serotonin receptors: A comparative iontophoretic study with LSD and serotonin. Neuropharmacology 16: 811-818.

Fernandez de Molina, A., M. Kuno, and E. R. Perl (1965) Antidromically evoked responses from sympathetic preganglionic neurones. J. Physiol. (Lond.) 180: 321-335.

Franz, D. N., B. D. Hare, and R. J. Neumayr (1978) Depression of sympathetic preganglionic neurons by clonidine: Evidence for stimulation of 5-HT receptors. Clin. Exp. Hypertens. 1: $115-140$

Fuxe, K., T. Hökfelt, P. Bolme, M. Goldstein, O. Johansson, G. Jonsson, P. Lidbrink, $\AA$. Ljungdahl, and Ch. Sachs (1975) The topography of central catecholamine pathways in relation to their possible role in blood pressure control. In Central Action of Drugs in Blood Pressure Regulation, D. S. Davies and J. L. Reid, eds., pp. 8-23, University Park Press, Baltimore.

Guyenet, P. G. (1980) The coeruleospinal noradrenergic neurons: Anatomical and electrophysiological studies in the rat. Brain Res. 189: 121-133.

Guyenet, P. G., and G. K. Aghajanian (1978) Antidromic identification of dopaminergic and other output neurons of the rat substantia nigra. Brain Res. 150: 69-84.

Haigler, H. J., and G. K. Aghajanian (1973) Mescaline and LSD: Direct and indirect effects on serotonin-containing neurons in brain. Eur. J. Pharmacol. 21: 53-60.

Hauesler, G. (1974) Clonidine-induced inhibition of sympathetic nerve activity: No indication for a central presynaptic or an indirect sympathomimetic mode of action. Naunyn Schmiedebergs Arch. Pharmacol. 286: 97-111.

Hauesler, G. (1977) Neuronal mechanisms influencing transmission in the baroreceptor reflex arc. Prog. Brain Res. 47: 95- 109.

Henning, M., and A. Rubenson (1971) Evidence that the hypotensive action of $\alpha$-methyl DOPA is mediated by central actions of methylnoradrenaline. J. Pharm. Pharmacol. 23: $407-411$.

Hökfelt, T., K. Fuxe, M. Goldstein, and O. Johansson (1974) Immunohistochemical evidence for the existence of adrenaline neurons in the rat brain. Brain Res. 66: 235-251.

Hongo, T., and R. W. Ryall (1966) Electrophysiological and micro-electrophoretic studies on sympathetic preganglionic neurons in the spinal cord. Acta Physiol. Scand. 68: 96-104.

Huber, J. F. (1936) Nerve roots and nuclear groups in the spinal cord of the pigeon. J. Comp. Neurol. 65: 43-91.

Kobinger, W. (1978) Central $\alpha$-adrenergic systems as targets for hypotensive drugs. Rev. Physiol. Biochem. Pharmacol. 81: 39-100.

Langer, S. Z., I. Cavero, and R. Massingham (1980) Recent developments in noradrenergic neurotransmission and its relevance to the mechanism of action of certain antihypertensive agents. Hypertension 2: 372-382.

Laubie, M., and H. Schmitt (1977) Sites of action of clonidine: Centrally mediated increase in vagal tone, centrally mediated hypotensive and sympathoinhibitory effects. Prog. Brain Res. 47: 337-348.

Loewy, A. D., and S. McKellar (1980) The neuroanatomical basis of central cardiovascular control. Fed. Proc. 39: 24952503.

Loewy, A. D., S. McKellar, and C. B. Saper (1979) Direct projections from the A5 catecholamine cell group to the intermediolateral cell column. Brain Res. 174: 309-314.

MacDonald, R. I., and D. H. Cohen (1970) Cells of origin of sympathetic pre- and postganglionic cardioaccelerator fibers in the pigeon. J. Comp. Neurol. 140: 343-358.

Madsen, P. W., B. D. Hare, C. Sangdee, and D. N. Franz (1980) Contrasting effects of clonidine and 5HTP on spinal sympathetic pathways. Soc. Neurosci. Abstr. 6: 166.

McLachlan, E. M., and G. D. S. Hirst (1980) Some properties of preganglionic neurons in upper thoracic spinal cord of the cat. J. Neurophysiol. 43: 1251-1265.

Miach, P. J., J. P. Dausse, and P. Meyer (1978) Direct biochemical demonstration of two types of $\alpha$-adrenoreceptor in rat brain. Nature 274: 492-494.

Neumayr, R. F., R. D. Hare, and D. N. Franz (1974) Evidence for bulbospinal control of sympathetic preganglionic neurons by monoaminergic pathways. Life Sci. 14: 793-806.

Pelayo, F., M. L. Ducobovich, and S. Z. Langer (1980) Inhibition of neuronal uptake reduces the presynaptic effects of clonidine but not of $\alpha$-methylnoradrenaline on the stimulationevoked release of ${ }^{3} \mathrm{H}$-noradrenaline from rat occipital cortex slices. Eur. J. Pharmacol. 64: 143-155.

Polosa, C. (1967) The silent period of sympathetic preganglionic neurons. Can. J. Physiol. Pharmacol. 45: 1033-1045.

Reis, D. J., N. Doba, D. W. Snyder, and M. A. Nathan (1977) Brain lesions and hypertension: Chronic lability and elevation of arterial pressure produced by electrolytic lesions and 6 hydroxydopamine treatment of nucleus tractus solitarii (NTS). Prog. Brain Res. 47: 169-197.

Rogawski, M. A., and G. K. Aghajanian (1980) Activation of lateral geniculate neurons by norepinephrine: Mediation by an $\alpha$-adrenergic receptor. Brain Res. 182: 345-359.

Ruffolo, R. R., E. L. Rosing, and J. E. Waddell (1979) Receptor interactions of imidazolines. I. Affinity and efficacy for alpha adrenergic receptors in rat aorta. J. Pharmacol. Exp. Ther. 209: 429-436.

Schmitt, H. (1977) The pharmacology of clonidine and related products. In Handbook of Experimental Pharmacology. Vol. 39: Antihypertensive Agents, F. Gross, ed., pp. 299 396, Springer-Verlag, New York.

Simmonds, M. A. (1974) Quantitative evaluation of responses to microiontophoretically applied drugs. Neuropharmacology 13: 401-406.

Smolen, A. J., and L. L. Ross (1978) The bulbospinal monoaminergic system of the chick: Degeneration in the sympathetic nucleus following surgical and chemical lesions. Brain Res. 139: 153-159.

Starke, K. (1977) Regulation of noradrenaline release by presynaptic receptor systems. Rev. Physiol. Biochem. Pharma. col. 77: 1-124.

Straughan, D. W. (1974) Convulsant drugs: Amino acid antagonism and central inhibition. Neuropharmacology 13: 495508 .

Taylor, D. G., and M. J. Brody (1976) Spinal adrenergic mechanism regulating sympathetic outflow to blood vessels. Circ. Res. Suppl. II 38: 10-20.

Taylor, D. G., and G. L. Gebber (1973) Sympathetic unit responses to stimulation of cat medulla. Am. J. Physiol. 225: $1138-1146$.

Terni, T. (1923) Ricerche anatomiche sul sistems nervosa autonoma degli uccelli. Arch. Ital. Anat. Embriol. 20: 433-510.

Van Zwieten, P. A. (1980) Pharmacology of centrally acting hypotensive drugs. Br. J. Clin. Pharmacol. 10: 135-205.

Wang, R. Y., C. DeMontigny, B. I. Gold, R. H. Roth, and G. K. Aghajanian (1979) Denervation supersensitivity to serotonin in rat forebrain: Single cell studies. Brain Res. 178: 479 497.

Young, W. S., and M. J. Kuhar (1980) Noradrenergic $\alpha_{1}$ and $\alpha_{2}$ receptors: Light microscopic autoradiographic localization. Proc. Natl. Acad. Sci. U. S. A. 77: 1696-1700.

Zivin, J. A., J. L. Reid, J. M. Saavedra, and I. J. Kopin (1975) Quantitative localization of biogenic amines in the spinal cord. Brain Res. 99: 293-301. 